\title{
On the bilateral trade effects of free trade agreements between the EU-15 and the CEEC-4 countries
}

\author{
Guglielmo Maria Caporale • Christophe Rault • \\ Robert Sova $\cdot$ Anamaria Sova
}

Published online: 3 April 2009

(C) Kiel Institute 2009

\begin{abstract}
The expansion of regionalism has spawned an extensive theoretical literature analysing the effects of free trade agreements (FTAs) on trade flows. In this paper we focus on FTAs (also called European agreements) between the European Union (EU-15) and the Central and Eastern European countries (CEEC-4, i.e. Bulgaria, Hungary, Poland and Romania) and model their effects on trade flows by treating the agreement variable as endogenous. Our theoretical framework is the gravity model, and the econometric method used to isolate and eliminate the potential endogeneity bias of the agreement variable is the fixed effect vector decomposition (FEVD) technique. Our estimation results indicate a positive and significant impact of LFTAs on trade flows. This finding is robust to the inclusion in the sample of a group of control countries (specifically Belarus, the Russian
\end{abstract}

G. M. Caporale $(\bowtie)$

Centre for Empirical Finance, Brunel University, West London UB8 3PH, UK

e-mail: Guglielmo-Maria.Caporale@brunel.ac.uk

G. M. Caporale

CESifo, Munich, Germany

G. M. Caporale

DIW, Berlin, Germany

C. Rault

LEO, University of Orléans, UMR 6221, BEM (Bordeaux Management School), Orléans, France

C. Rault

EDHEC (Ecole des Hautes Etudes Commerciales), Lille Cedex, France

R. Sova

CES, Sorbonne University, A.S.E and E.B.R.C, Paris, France

A. Sova

CES, Sorbonne University, E.B.R.C, Paris, France 
Federation and the Ukraine) that did not sign an FTA. Besides, we show that trade growth after the FTA agreement with the EU was signed exceeded trade growth of the control group of countries, which did not become members.

Keywords Regionalisation - European integration · Panel data methods

\section{JEL Classification $\mathrm{F} 13 \cdot \mathrm{F} 15 \cdot \mathrm{C} 23$}

\section{Introduction}

Following the new wave of regionalisation in the 1980s, regional integration has again been extensively investigated both in the theoretical and empirical literature. Recent analyses are based on Viner's (1950) framework but also include theoretical ideas from the new trade theory and economic geography, being concerned with the impact of integration on global welfare. The innovation compared to the first wave studies consists in taking into account the dynamic effects of geographical size, noneconomic gains, industrial localisation, and economies of scale.

The enlargement of the European Union (EU) to 27 countries which was proposed during the 1990s was unprecedented in terms of the number of countries and the changes which were implied, hence representing a challenge for both EU member countries and Central and Eastern European Countries (CEEC). It was a very important development for the future of the European continent. From a political point of view, it ensured stability after the troubled years of the Cold War. From an economic point of view, because of the size and the population of the countries involved and the development gap relative to the EU, the transition towards a market economy has not been without difficulties for the CEEC.

There exists already an extensive literature analysing the effects of regional free trade agreements (FTAs) on trade flows and stressing the role of regionalisation. However, the evidence is mixed. Most studies assume that the FTA formation (i.e. the choice of partner countries) is exogenous, but some papers highlight the potential endogeneity bias in estimating the effects of FTAs on trade volumes (Magee 2003; Baier and Bergstrand 2004). Regional agreements require the assent of two governments. According to Grossman and Helpman (1995) an FTA assumes a relative balance in the potential trade between the partner countries.

In this paper we focus on association agreements between four Central and Eastern European countries (CEEC-4, i.e. Bulgaria, Hungary, Poland and Romania) and European Union member states (EU-15, i.e. Austria, Belgium-Luxemburg, Denmark, the United Kingdom, Finland, France, Germany, Greece, the Netherlands, Ireland, Italy, Portugal, Spain, Sweden) in the context of EU enlargement towards the East, taking into account the conditions under which countries agree on FTAs, and their effects on trade. Our econometric analysis is based on the gravity model and tries to determine the effects of association agreements on trade flows treating FTAs as endogenous. We are particularly interested in whether such European agreements have increased trade flows between their members and, if so, by how much. To address these issues, we examine the bilateral trade volume introducing a dummy 
variable which represents the association agreement. In addition, we investigate the robustness of the association agreement variable in two different ways by considering an extended sample of countries including three countries (Belarus, the Russian Federation and the Ukraine) that did not sign an FTA with EU-15 and using different estimations methods. Also, we compare the trade growth between the EU-15 and CEEC-4 countries and the trade growth between the EU-15 and other countries which did not have a trade agreement. Further, we use panel data techniques to isolate and eliminate the potential endogeneity bias of the agreement variable.

The contribution of this paper is threefold:

(i) In contrast to previous studies we rely on an estimation method, i.e. the fixed effect vector decomposition (FEVD), that enables us to isolate and eliminate the potential endogeneity bias of the agreement variable, thereby obtaining more robust results. The agreement variable is here treated as endogenous, unlike in earlier studies.

(ii) The sample period has been extended and includes additional observations, spanning the period 1987-2005.

(iii) We check the robustness of the effects of FTAs by also considering a group of control countries (Belarus, the Russian Federation and the Ukraine) which did not conclude an agreement with the EU; besides, we examine whether bilateral trade between the CEEC-4 and EU-15 is higher than between the EU-15 and this group of control countries.

The remainder of the paper is organised as follows: In Sect. 2 we discuss briefly European agreements and the issue of endogeneity in regional agreements. In Sect. 3 we outline the theoretical framework, i.e. the gravity model. In Sect. 4 we discuss alternative econometric methods to estimate gravity models, whilst the empirical analysis is presented in Sect. 5. Section 6 summarises the main findings and offers some concluding remarks.

\section{European agreements and the endogeneity issue}

EU enlargement is not a new phenomenon, as the EU has already been enlarged several times since its creation: the year 1973 marked the accession of Denmark, the United Kingdom and Ireland; 1981, of Greece; 1986, of Spain and Portugal; 1995, of Austria, Sweden and Finland. However, EU enlargement towards the East is different both politically and economically, as it is the first time that countries belonging to the old communist bloc have applied for EU membership, and on this occasion integration has increased by as much as a third the EU population and territory (and to a lesser extent its wealth).

The EU proposed two basic strategic objectives for enlargement. Firstly, the creation of a Europe which guarantees peace, stability, democracy and respect of the human rights of minorities. Secondly, the creation of an open and competitive market able to improve the standard of living in the CEEC, gradually achieving real convergence. As a first step, in the early 1990s all candidate countries signed bilateral "European agreements" or "Association agreements" with the EU creating 
preferential trade relationships. ${ }^{1}$ These included a time schedule for trade liberalisation between the signatories, with the EU agreeing to reduce barriers more quickly than the CEEC. However, initially tariff and non-tariff barriers were not dismantled for sensitive sectors such as agriculture and textiles.

The expansion of regionalism has spawned an extensive literature on the effects of FTAs on trade flows and the choice of countries to form a preferential trade agreement. This literature focuses on welfare-enhancing and political arguments to explain association agreements. Since Viner (1950) most studies have analysed the welfare gains or losses from FTAs for member countries. FTAs have a positive impact on welfare if trade creation exceeds trade diversion. Factors accounting for the probability that two countries sign a regional agreement can be divided in three groups: (i) geography factors, (ii) intra-industry trade determinants, and (iii) interindustry trade determinants. ${ }^{2}$ In brief, two countries are more likely to sign an agreement if they are closer geographically, similar in size and differ in terms of factor endowment ratios:

(i) The net welfare gain is higher the closer the two countries are, because of trade creation. Several studies (Frankel et al. 1996; Frankel and Wei 1998) include geographical proximity in their analysis of an FTA formation. The rationale is the existence of transport costs (Helpman and Krugman 1985), leading to the concept of "natural trade partners" based on geographical distance. ${ }^{3}$ Krugman (1991) shows that in the case of agreements between geographically close countries trade creation is sizable (see also Wonnacott and Lutz 1989), but the concept of "natural" partners has attracted criticism, on the grounds that geographical proximity and initially high trade volumes do not necessarily ensure trade creation after FTA formation (see Bhagwati and Panagariya 1996).

(ii) The larger and more similar in economic size the two countries signing a trade agreement are, the higher the welfare gains from trade creation, which are achieved by exploiting economies of scale in the presence of differentiated products.

(iii) The greater the difference in endowment ratios between two countries, the higher the potential welfare gains from trade creation reflecting traditional comparative advantages.

Consequently, countries which sign a regional agreement tend to have similar economic characteristics, which leads to trade creation and welfare gains.

Non-economic objectives can also be behind regional agreements. ${ }^{4}$ In particular, better political decision-making, a guarantee of policy irreversibility, and bigger negotiating power with third parties could also explain such agreements (especially

\footnotetext{
1 Hungary (1991), Poland (1991), Romania (1993), the Czech Republic (1993), Slovakia (1993), Bulgaria (1993), Latvia (1995), Estonia (1995), Lithuania (1995) and Slovenia (1995).

2 See Baier and Bergstrand (2004).

3 These models emphasise the role of transport costs in maximising/minimising the welfare of countries (proximity of/distance between partners implies low/high transport costs).

${ }^{4}$ See Johnson (1965), Cooper and Massell (1965), Wonnacott and Lutz (1989), Magee (2003) and Baier and Bergstrand (2004).
} 
when the agreement takes the form of a customs union with a common exterior tariff-see Schiff and Winters (1998). Also, democratic countries are more interested in consumers' welfare and more likely to sign agreements with other democratic partners. Further, De Melo et al. (1993) showed that regional agreements make the implementation of policies more effective owing to a dilution effect of preferences: the lobby capacity of interest groups is lower in a regional as opposed to a national framework. Finally, such agreements make domestic policy reforms irreversible (Fernández and Portes 1998).

There exists already an extensive literature analysing the effects of regional free trade agreements (FTAs) on trade flows and stressing the role of regionalisation. Rose (2004) in his paper estimates the effect of multilateral trade agreements-the World Trade Organization (WTO), and the Generalized System of Preferences (GSP)—on international trade. He uses a standard gravity model of bilateral trade and a large panel data set. His findings reveal that there is little evidence that GATT/WTO membership has a substantial positive effect on trade. The GSP and the regional trade associations typically seem to have a much larger effect than the multilateral GATT/ WTO system indicating that trade at least doubles with membership.

The first empirical studies analysing the trade effects of an FTA included an FTA dummy variable in a gravity model. Most of them treated FTA formation (choice of partner countries) as exogenous. The evidence was mixed. For instance, some studies found a significant impact of EC (European Community) agreements on trade flows between members (Aitken 1973), whilst others concluded that this effect was insignificant (Bergstrand 1985) or even negative (Frankel 1997). This highlighted the potential endogeneity bias affecting the preferential agreement variable, and subsequently a few studies tried to address the endogeneity issue by considering the role of economic factors, democratic freedom, and transport costs in the decision to conclude a regional agreement. Baier and Bergstrand (2004) found that pairs of countries that sign an agreement tend to share common economic characteristics, which results in net trade creation and welfare growth. Magee (2003) measured the effects of preferential agreements on trade volumes treating FTAs as endogenous, estimating a system of simultaneous equations with 2SLS. He found that it is likely that two countries will sign an agreement if they are closer geographically, are similar in size and are both democracies.

Ghosh and Yamarik (2004) tried to test the robustness of the regional agreement effect by using cross-section data. They concluded that its effect may be over- or underestimated owing to the potential endogeneity of this variable. These findings were confirmed by Baier and Bergstrand (2007), who pointed out that the regional agreement variable is not exogenous and the estimation of a gravity model using cross-section data for investigating the quantitative effect of this variable on trade flows can be biased because of unobservable heterogeneity or/and omitted variables. The bias resulting from not considering this variable as endogenous is an important issue; it can be the consequence of omitted variables that can be correlated with the regional agreement variable. Panel data (fixed effects) methods were shown to be suitable to take endogeneity into account.

Given the theoretical and empirical literature presented above concerning the FTA formation, we now focus on the specific conditions which determined the 
association of the CEEC-4 with the EU-15. The EU enlargement to include the CEEC countries was one of the Nice Summit challenges. This enlargement has contributed to overcoming the artificial division of Europe, and has finally given the CEEC countries, which have always been part of Europe, a chance to participate in the European project.

The collapse of the COMECON (Council for Mutual Economic Assistance) put an end to trade on the basis of planned exchanges, and to major industrial projects and/or cooperation contracts based on production complementarity without considering demand and supply. It has led to major transformations with the introduction of a market economy, reintegration of the CEEC into the European economy, and changes in the geography of the EU. On their part, the Western European countries have turned more towards the CEEC countries, a dynamic and accessible market. Both trade reorientation and EU enlargement have led to the signing of association agreements, the first step towards integration. In fact, the ultimate goal of the agreements is the accession of these countries. Despite the similar framework and structure of the agreements, allowance has been made for differences across countries, especially in terms of free trade, financial cooperation and sectoral policies.

In conclusion, in the context of the EU enlargement, the economic and political transition of the CEECs to a market economy and towards a democratic system and the geographical proximity to the EU-15 core represent important factors that determine the signing of association agreements. Even if the literature indicates the importance of economic size in the FTA formation, in this case we can see the existence of differences in factor endowment between the EU and the CEEC, which can generate trade flows based on comparative advantage, and therefore increase the wealth. As international trade is one of the factors driving economic growth, we are interested in examining the effects on trade of FTAs between the CEEC-4 and the EU-15.

\section{Trade flow effects of FTAs: the gravity model}

Our theoretical framework to examine the trade flows effects of FTAs (treating association agreements as endogenous) is the gravity model, ${ }^{5}$ in which trade flows from country $i$ to country $j$ are a function of the supply of the exporter country and of the demand of the importer country and trade barriers. In other words, national incomes of two countries, transport costs (transaction costs) and regional agreements are the basic determinants of trade.

Initially inspired by Newton's gravity law, gravity models have become essential tools in the analysis of the effects of regional agreements on trade flows. The first applications were rather intuitive, without great theoretical claims. These included the contributions of Tinbergen (1962) and Pöyhönen (1963). But these studies were criticised for their lack of robust theoretical foundations. Subsequently, new international trade theory provided theoretical justifications for these models in

\footnotetext{
5 The popularity of the gravity model is highlighted by Eichengreen and Irwin (1995) who consider it "the workhorse for empirical studies of regional integration".
} 
terms of increasing returns of scale, imperfect competition and geography (transport costs).

Linnemann (1966) proposed a gravity model derived from a Walrasian, general equilibrium model. He explained exports of country $i$ to country $j$ in terms of the interaction of three factors: potential supply of exports of country $i$, potential demand of imports from the country $j$ and a factor representing trade barriers. Potential export supply is a positive function of the exporting country's income level and can also be interpreted as a proxy for product variety. Potential import demand is a positive function of the importing country's income level. Barriers to trade are a negative function of trade costs, transport costs, tariffs. The model takes the following form:

$$
X_{i j}=e^{\beta_{0}} Y_{i}^{\beta_{1}} N_{i}^{-\beta_{2}} Y_{j}^{\beta_{3}} N_{j}^{-\beta_{4}} D_{i j}^{-\beta_{5}} e^{\sum_{k} \gamma^{k} P_{k i j}}
$$

where $Y$ represents country income, $N$ represents the population, $D$ is the geographical distance and $P_{k}$ includes dummy variables. Anderson (1979), Bergstrand (1985) and Helpman and Krugman (1985) provided further theoretical justifications for this model.

This equation was extended by Bergstrand (1989) by including per capita income, which is an indicator of demand sophistication (demand for luxury vs. necessity goods):

$$
X_{i j}=e^{\beta_{0}} Y_{i}^{\beta_{1}}\left(\frac{Y_{i}}{N_{i}}\right)^{-\beta_{2}} Y_{j}^{\beta_{3}}\left(\frac{Y_{j}}{N_{j}}\right)^{-\beta_{4}} D_{i j}^{-\beta_{5}} e^{\sum_{k} \gamma^{k} P_{k i j}}
$$

where $X_{i j}$ represents exports of country $i$ to country $j, \beta_{0}$ is the intercept, $Y_{i}$ and $Y_{j}$ are the GDP of country $i$ and $j$, respectively, $\left(Y_{i} / N_{i}\right)$ and $\left(Y_{j} / N_{j}\right)$ stand for GDP per capita of country $i$ and $j$, respectively, $D_{i j}$ represents the geographical distance between the economic centres of two partners, $P_{k i j}$ stands for other variables such as common language and historical bonds.

\section{Econometric issues}

The regionalism issue was most frequently examined using a gravity model including a dummy variable for regional agreements. ${ }^{6}$ Most studies estimating a gravity model applied the ordinary least square (OLS) method to cross-section data. Recently, several papers have argued that standard cross-section methods lead to biased results because they do not account for heterogeneity. For instance, the impact of historical, cultural and linguistic links on trade flows is difficult to quantify. On the other hand, the potential sources of endogeneity bias in gravity model estimations fall under three categories: omitted variables, simultaneity, and measurement error (Wooldridge 2002).

\footnotetext{
${ }^{6}$ Baldwin (1994), Frankel (1997), Soloaga and Winters (2001), Glick and Rose (2002), Rault, Sova, and Sova (2007a, 2007b) and Carrère (2006).
} 
Matyas (1997) points out that the cross-section approach is affected by misspecification and suggests that the gravity model should be specified as a "three-way model" with exporter, importer and time effects (random or fixed ones). Egger (2000) argues that panel data methods are the most appropriate for disentangling time-invariant and country-specific effects. Egger and Pfaffermayr (2003) underline that the omission of specific effects for country pairs can bias the estimated coefficients. An alternative solution is to use an estimator to control bilateral specific effects as in a fixed effect model (FEM) or in a random effect model (REM). The advantage of the former is that it allows for unobserved or misspecified factors that simultaneously explain the trade volume between two countries and lead to unbiased and efficient results. ${ }^{7}$ The choice of the method (FEM or REM) is determined by economic and econometric considerations. From an economic point of view, there are unobservable time-invariant random variables, difficult to be quantified, which may simultaneously influence some explanatory variables and trade volume. From an econometric point of view, the inclusion of fixed effects is preferable to random effects because the rejection of the null assumption of no correlation between the unobservable characteristics and explanatory variables is less plausible (Baier and Bergstrand 2007).

Another method which has gained considerable acceptance among economists (Egger and Pfaffermayr 2004) is the Hausman-Taylor's panel one incorporating time-invariant variables correlated with bilateral specific effects (see for instance, Hausman and Taylor (1981), Wooldridge (2002) and Hsiao (2003)). Plümper and Troeger (2004) have proposed a more efficient method called "the fixed effect vector decomposition (FEVD)" to accommodate time-invariant variables. Using Monte Carlo simulations they compared the performance of the FEVD method to some other existing techniques, such as the fixed effects, or random effects, or Hausman-Taylor method. Their results indicate that the most reliable technique for small samples is FEVD if time-invariant variables and the other variables are correlated with specific effects, which is likely to be the case in our study. Consequently, we use this technique for the empirical analysis.

Next we provide more details of the alternative methods mentioned above, i.e. random effect estimator (REM), fixed effect estimator (FEM) and fixed effect vector decomposition (FEVD).

\subsection{Within estimator and random estimator (FEM and REM)}

In the presence of correlation of the unobserved characteristics with some of the explanatory variables the random effect estimator leads to biased and inconsistent estimates of the parameters. To eliminate this correlation it is possible to use a traditional method called "within estimator or fixed effect estimator" which consists in transforming the data into deviations from individual means. In this case, even if there is correlation between unobserved characteristics and some explanatory variables, the within estimator provides unbiased and consistent results.

The fixed effect model can be written as

\footnotetext{
${ }^{7}$ Egger (2000, 2002).
} 
$y_{i t}=\sum_{k=1}^{K} \beta_{k} x_{i t k}+\alpha_{i}+u_{i t}$,

$t=1,2, \ldots, T ; k=1,2, \ldots, K$ regressors $; i=1,2, \ldots, N$ individuals,

where $\alpha_{i}$ denotes individual effects fixed over time and $u_{i t}$ is the disturbance term.

If we substract from (3) the average over time of (3) we obtain the fixed effects transformation as:

$$
y_{i t}-\bar{y}_{i}=\sum_{k=1}^{K} \beta_{k}\left(x_{i t k}-\bar{x}_{i k}\right)+\left(u_{i t}-\bar{u}_{i}\right)
$$

In the fixed effect transformation, the unobserved effect, $\alpha_{i}$, disappears, which yields unbiased and consistent results.

The random model has the same form as before,

$$
Y_{i t}=\hat{a}_{0}+\hat{a}_{1} x_{i t 1}+\hat{a}_{2} x_{i t 2}+\cdots+\hat{a}_{k} x_{i t k}+\dot{a}_{i}+u_{i t}
$$

where an intercept is included so that the unobserved effect, $a_{i}^{\prime}$, has a zero mean. Equation 5 becomes $a$ random effect model when we assume that the unobserved effect $a_{i}^{\prime}$ is uncorrelated with each explanatory variable:

$$
\operatorname{Cov}\left(x_{i t k}, \dot{a}_{i}\right)=0, \quad t=1,2, \ldots, T ; \quad j=1,2, \ldots, k .
$$

The Hausman $\chi^{2}$-test consists in testing the null hypothesis of no correlation between unobserved characteristics and some explanatory variables and allows us to make a choice between random estimator and within estimator. The within estimator has, however, two important limits: firstly, it may not estimate the time-invariant variables that are eliminated by data transformation; secondly, the fixed effect estimator ignores variations across individuals. The individual's specificities can be correlated or not with the explanatory variable. In traditional methods these correlated variables are replaced with instrumental variables uncorrelated to unobservable characteristics.

\subsection{Fixed effect vector decomposition (FEVD)}

Plümper and Troeger (2004) suggest an alternative to the estimation of timeinvariant variables in the presence of unit effects, namely the model discussed in Hsiao (2003). It is known that unit fixed effects are a vector of the mean effect of omitted variables, including the effect of time-invariant variables. It is therefore possible to regress the unit effects on the time-invariant variables to obtain approximate estimates for invariant variables. Plümper and Troeger (2004) propose a three-stage estimator, where the second stage only aims at the identification of the unobserved parts of the unit effects, and then uses the unexplained part to obtain unbiased pooled OLS (POLS) estimates of the timevarying and time-invariant variables only in the third stage. The unit effect vector is decomposed into two parts: a part explained by time-invariant variables and an unexplainable part (the error term). The model proposed by Plümper and Troeger (2004) yields unbiased and consistent estimates of 
the effect of time-varying variable which are unbiased for time-invariant variables if the unexplained part of unit effects is uncorrelated with timeinvariant variables.

This model has the robustness of fixed effect model and allows for the correlation between the time-variant explanatory variables and the unobserved individual effects. In brief, the fixed effect vector decomposition (FEVD) proposed by Plümper and Troeger (2004) involves the three following steps:

(i) Estimation of the unit fixed effects by the FEM excluding the time-invariant explanatory variables;

(ii) Regression of the fixed effect vector on the time-invariant variables of the original model (by OLS);

(iii) Re-estimation of the original model by POLS, including all time-variant explanatory variables, time-invariant variables and the unexplained part of the fixed effect vector. The third stage is required to control for multicollinearity and to adjust the degrees of freedom. ${ }^{8}$

A general form of regression equation can be written as:

$$
y_{i t}=\alpha+\beta \mathrm{X}_{i t}+\gamma \mathrm{Z}_{i}+\varepsilon_{i t}
$$

where $\beta \mathrm{X}_{i t}$ denotes the time-variant variable vector, $\gamma \mathrm{Z}_{i}$ the time-invariant variable vector and $\varepsilon_{i t}$ the normal distributed error component.

In the presence of unobserved time-invariant variables the Eq. 7 can be written as

$$
y_{i t}=\alpha+\beta \mathrm{X}_{i t}+\gamma \mathrm{Z}_{i}+u_{i}+\varepsilon_{i t}
$$

where $u_{i}$ denotes the unobserved time-invariant variable whose unobserved effects are a random variable rather than an estimated parameter.

The FEVD approach is implemented as follows:

\subsubsection{First step}

Recall the data generating process of Eq. 7. The within estimator quasi de-means the data and removes the individual effects $u_{i}$ :

$$
y_{i t}-\bar{y}_{i}=\beta_{k} \sum_{k=1}^{K}\left(x_{k i t}-\bar{x}_{k i}\right)+\varepsilon_{i t}-\bar{\varepsilon}_{i} \equiv \tilde{y}_{i t}=\beta_{k} \sum_{k=1}^{K} \tilde{x}_{k i}+\tilde{\varepsilon}_{i t}
$$

The variance not used by the fixed effect estimator is most important.

The unit effects are explained by:

$$
\hat{u}_{i}=\bar{y}_{i}-\hat{\beta}_{k}^{\mathrm{FEM}} \sum_{k=1}^{K} \bar{x}_{k i t}=\hat{\alpha}+\gamma_{j} \sum_{j=1}^{J} z_{j i}+\eta_{i}+\overline{\hat{\varepsilon}}_{i}
$$

\footnotetext{
${ }^{8}$ The programme STATA proposed by the authors executes all three steps and adjusts the variancecovariance matrix. Options like AR (1) error-correction and robust variance-covariance matrix are allowed.
} 
where $\eta_{i}$ is the unexplained part of the unit effects and $\bar{\varepsilon}_{i}$ are the average unit means of the FEM estimation (indicating panel heteroskedasticity if $\bar{\varepsilon}_{i} \neq 0$ ).

\subsubsection{Second step}

Given Eq. 10, it is simple to regress the $\hat{u}_{i}$ on the $z$-variables.

$$
\hat{u}_{i}=\omega+\gamma_{j} \sum_{j=1}^{J} z_{j i}+\eta_{i} \text { and } \hat{\eta}_{i}=\hat{u}_{i}-\varpi-\gamma_{j} \sum_{j=1}^{J} z_{j i}
$$

where $\omega$ is the intercept of the stage 2 equation and $\eta_{i}$ is the unexplained part of the unit effects as in Eq. 10. Equations 10 and 11 show that the exclusion of variables that are simultaneously correlated with the unit-effects $\hat{u}_{i}$ and the time-invariant variables $z_{\mathrm{i}}$ lead to biased estimates. In other words, the estimates are unbiased only if $\eta_{i} \cong 0$ for all $i$ or if $\mathrm{E}\left(z_{i} \mid \eta_{i}\right)=\mathrm{E}\left(z_{i}\right)=0$.

\subsubsection{Third step}

The full model is re-run without the unit effects but including the decomposed unit fixed effect vectors comprising $\hat{\eta}_{i}$ obtained in step 2 . The third step is estimated by pooled OLS (or Prais-Winston in the presence of serial correlation).

$$
y_{i t}=\alpha+\beta_{k} \sum_{k=1}^{K} x_{k i t}+\gamma_{j} \sum_{j=1}^{J} z_{j i}+\hat{\eta}_{i}+\varepsilon_{i t}
$$

By construction, $\hat{\eta}_{i}$ is no longer correlated with the vector of the $z$ 's.

By including the error term of step 2 it is possible to account for individual specific effects that cannot be observed. The coefficient of $\hat{\eta}_{i}$ is either equal to 1.0 or at least close to 1.0 (by accounting for serial correlation or panel heteroskedasticity) in step 3 . Estimating stage 3 by pooled OLS further requires that heteroskedasticity and serial correlation must be eliminated beforehand.

At least in theory this method has three obvious advantages (Plümper and Troeger 2004): (i) the fixed effect vector decomposition does not require prior knowledge of the correlation between time-variant explanatory variables and unit specific effects, (ii) the estimator relies on the robustness of the withintransformation and does not need to meet the orthogonality assumptions (for time-variant variables) of random effects, and (iii) FEVD estimator maintains the efficiency of POLS.

Essentially, FEVD produces unbiased estimates of time-varying variables, regardless of whether they are correlated with unit effects or not, and unbiased estimates of time-invariant variables that are not correlated. The estimated coefficients of the time-invariable variables correlated with unit effects, however, suffer from omitted variable bias. To summarise, FEVD produces less biased and more efficient coefficients. The main advantages of FEVD come from its lack of bias in estimating the coefficients of time-variant variables that are correlated with unit-effects. 


\section{Empirical analysis}

\subsection{The econometric strategy}

The econometric model we adopt in order to identify and to quantify the impact of the association agreement on trade flows between the EU-15 and CEEC-4 countries was chosen taking into account our sample of data, the potential endogeneity of the variables, the existence of unobservable bilateral characteristics which might or might not be correlated with the explanatory variables, and multicollinearity.

Our econometric specification is the following:

$$
\begin{aligned}
\log \left(Y_{i j t}\right)= & \alpha_{0}+\alpha_{1} \log \left(\mathrm{GDP}_{i t}\right)+\alpha_{2} \log \left(\mathrm{GDP}_{j t}\right)+\alpha_{3} \log \left(\mathrm{GDPC}_{i t}\right)+\alpha_{4} \log \left(\mathrm{GDPC}_{j t}\right) \\
& +\alpha_{5} \log \left(\mathrm{Dist}_{i j}\right)+\alpha_{6} \mathrm{Stp}_{i t}+\alpha_{7} \mathrm{Llk}_{i j}+\alpha_{8} \mathrm{Acc}_{i j t}+u_{i j}+\theta_{t} \\
& +\varepsilon_{i j t}(i=1, \ldots N ; t=1, \ldots T)
\end{aligned}
$$

In this specification, the average value of bilateral trade $\left(Y_{i j t}\right)$ is the dependent variable. The explanatory variables used are the gross domestic product of the two partners $\left(\mathrm{GDP}_{i t}\right),\left(\mathrm{GDP}_{j t}\right)$, geographic distance $\left(\mathrm{Dist}_{i j}\right)$, income per capita $\left(\mathrm{GDPC}_{i t}\right.$ $\mathrm{GDPC}_{j t}$ ), political stability (Stp), landlocked countries (Llk) and the dichotomous variable association agreement $\left(\mathrm{Acc}_{i j t}\right)$.

The notation is the following:

- $Y_{i j t}$ denotes the average value of bilateral trade between countries $i$ and $j$ at time $t$ with $i \neq j$ (millions of dollars);

- $\alpha_{\mathrm{o}}$ is the intercept;

- $\mathrm{GDP}_{i t}, \mathrm{GDP}_{j t}$ represent the gross domestic product of country $i$ and country $j$ (millions of dollars);

- $\mathrm{GDP}_{i t} / N_{i t}, \mathrm{GDP}_{j t} / N_{j t}$ are the GDP per capita of country $i$ and country $j$;

- $\quad$ Dist $_{i j}$ represents the distance between country $i$ and country $j$ (kilometres);

- $\operatorname{Acc}_{i j t}$ is a dummy variable that is equal to 1 if country $i$ and country $j$ have concluded a regional agreement at time $t$, and zero otherwise;

- $\operatorname{Stp}_{i j t}$ is a dummy variable which is equal to 1 if country has political stability and zero otherwise;

- $\mathrm{Llk}_{i j}$ is a dummy variable representing the number of landlocked countries in the country pair $(0,1$ or 2$)$;

- $u_{i j}$ is a bilateral specific effect $(i=1,2, \ldots, N, j=1,2, \ldots, M)$;

- $\theta_{t}$ is a time specific effect $(t=1, \ldots, T)$;

- $\varepsilon_{i j t}$ is the disturbance term, which is assumed to be normally distributed with a zero mean and a constant variance for all observations and to be uncorrelated.

To assess the robustness of our results on the effects of FTAs we include in our sample a control group of countries, specifically Belarus, the Russian Federation and the Ukraine, i.e. three countries, which belonged in the past to the Communist bloc and have then introduced market reforms but did not sign an FTA with the EU. More precisely, we test whether the association dummy is still significant if one considers the period where all CEEC-4 have an $\operatorname{Acc}_{i j t}$ dummy of 1 and where additional countries that did not sign an FTA are added to the estimation sample 
with an $\mathrm{Acc}_{i j t}$ dummy of 0 . The Acc $\mathrm{A}_{i j t}$ dummy variable measures the impact of the association agreement on trade between members. The estimated equation is the same as (13) with the $\mathrm{Acc}_{i j t}$ dummy now defined as explained above.

Another possible way of checking robustness is to make a comparison between growth in trade between the EU and the countries that signed an FTA (i.e. the CEEC-4) and some others that did not (here Belarus, the Russian Federation and the Ukraine). For this purpose, we introduce in Eq. 14 two dummy variables. ${ }^{9}$ In this case, the equation to be estimated writes as follows:

$$
\begin{aligned}
\log \left(Y_{i j t}\right)= & \alpha_{0}+\alpha_{1} \log \left(\mathrm{GDP}_{i t}\right)+\alpha_{2} \log \left(\mathrm{GDP}_{j t}\right)+\alpha_{3} \log \left(\mathrm{GDPC}_{i t}\right)+\alpha_{4} \log \left(\mathrm{GDPC}_{j t}\right) \\
& +\alpha_{5} \log \left(\mathrm{Dist}_{i j}\right)+\alpha_{6} \mathrm{Stp}_{i t}+\alpha_{7} \mathrm{Llk}_{i j}+\alpha_{8} \mathrm{Acc}_{i j t}+\mathrm{Accn}_{i j t}+u_{i j}+\theta_{t} \\
& +\varepsilon_{i j t}(i=1, \ldots N ; t=1, \ldots T)
\end{aligned}
$$

where:

- $\quad \operatorname{Acc}_{i j t}$ is a dummy variable that is equal to 1 if country $i$ and country $j$ have concluded a regional agreement at time $t$, and zero otherwise.

- $\operatorname{Accn}_{i j t}$ is a dummy variable that is equal to 1 if one country has a regional agreement and its partner country does not at time $t$, and zero otherwise.

The first dummy variable measures the impact of the agreement on trade between FTA' members and the second one measures the trade effect between a member country and another which is not.

The data source is the CHELEM-French CEPII data base for GDP and population; the CEPII data base for geographic distance and Freedom House for political stability. The estimation period goes from 1987 to 2005, i.e. 19 years for a sample of EU-15 ${ }^{10}$ and 4 CEEC countries ${ }^{11}$ for the first set of estimates. For the second we have a sample from 1991 to 2005 owing to fewer observations being available for the Russian Federation and the Ukraine. We construct a panel with two dimensions: country pairs and years.

\subsection{Estimation results}

This section summarises the results from the estimation of the gravity model. We used panel data techniques for eliminating the endogeneity bias, and applied different panel data econometric methods such as fixed effect model (FEM), random effect model (REM) and fixed effects vector decomposition (FEVD) in order to check the robustness of our estimation technique and also of our results (see Tables 1, 2).

Table 1 shows the impact of FTAs on bilateral trade between EU-15 and CEEC-4. The aggregate estimation indicates a positive effect of the association agreement

\footnotetext{
9 Rose (2004) also compares trade patterns for countries in the GATT/WTO with those outside the system using two dummy variables, one to measure the trade effect if both countries are GATT/WTO and the other if one country is a member and the other is not.

${ }^{10}$ EU-15: Austria, Belgium-Luxemburg, Denmark, the United Kingdom, Finland, France, Germany, Greece, the Netherlands, Ireland, Italy, Portugal, Spain, Sweden.

11 Bulgaria, Hungary, Poland, Romania.
} 
Table 1 The impact of the association agreement on bilateral trade between EU-15 and CEEC-4

\begin{tabular}{|c|c|c|c|}
\hline Variables & $\begin{array}{l}\text { FEM } \\
(1) \\
Y_{i j t}\end{array}$ & $\begin{array}{l}\text { REM } \\
(2) \\
Y_{i j t}\end{array}$ & $\begin{array}{l}\text { FEVD } \\
(3) \\
Y_{i j t}\end{array}$ \\
\hline $\mathrm{GDP}_{i t}$ & $1.453(3.45)^{* * *}$ & $0.701(5.52)^{* * *}$ & $1.453(3.44)^{* * *}$ \\
\hline $\mathrm{GDP}_{j t}$ & $1.107(2.97)^{* * *}$ & $0.977(13.32)^{* * *}$ & $1.107(2.97)^{* * *}$ \\
\hline Dist $_{i j}$ & $0.000()$. & $-1.447(8.07)^{* * *}$ & $-1.139(2.57)^{* *}$ \\
\hline $\mathrm{GDPC}_{i t}$ & $0.660(1.89)^{*}$ & $1.424(8.03)^{* * *}$ & $0.660(2.64)^{* *}$ \\
\hline $\mathrm{GDPC}_{j t}$ & $0.816(2.03)^{* *}$ & $0.881(5.68)^{* * * *}$ & $0.816(56.25)^{* * *}$ \\
\hline $\mathrm{Llk}_{i j}$ & $0.000()$. & $-0.191(2.30)^{* *}$ & $-0.031(1.83)^{*}$ \\
\hline $\operatorname{Stp}_{i t}$ & $0.160(11.07)^{* * *}$ & $0.159(11.79)^{* * *}$ & $0.160(6.06)^{* * *}$ \\
\hline $\operatorname{Acc}_{i j t}$ & $0.204(12.10)^{* * *}$ & $0.201(12.29)^{* * *}$ & $0.204(18.57)^{* * *}$ \\
\hline Constant & $-17.626(19.99)^{* * *}$ & $-12.101(15.56)^{* * * *}$ & $-13.993(182.82)^{* * *}$ \\
\hline Observations & 1,064 & 1,064 & 1,064 \\
\hline$R$-squared & 0.82 & 0.87 & 0.96 \\
\hline Fischer Prob $>F$ & $38.37(0.00)$ & - & - \\
\hline Hausman Prob $>\chi^{2}$ & - & $13.08(0.04)$ & - \\
\hline
\end{tabular}

As explained in the main text, the FEVD method is the preferred one, the others (FEM and REM) are reported for comparison purposes and to check the robustness of the results to the estimation technique used

Absolute value of $t$ statistics in parentheses

* Significant at $10 \%$;* Significant at 5\%; *** Significant at $1 \%$

variable on trade flows, in accordance with previous studies. ${ }^{12}$ This is a standard result consistent with the theory of regional integration: membership of the FTA facilitates trade exchanges between the partners. The coefficients are statistically significant and have the expected signs consistent with the gravity model: a positive effect on trade flows of country size, income per capita, political stability and association agreement, and a negative impact of geographical distance. The effect of the association agreement is positive and the estimated coefficient is 0.204 (see column (3) of Table 1), which indicates that the agreement results in a $23 \%$ increase ${ }^{13}$ in trade between the members. Thus, there is clear evidence that the agreement has increased trade volume between the EU-15 and CEEC-4 countries.

We assessed the robustness of our results using data for a larger group of countries (also including Belarus, the Russian Federation and the Ukraine) (see column (3) of Table 2). Since the FEVD method produces more robust estimates in what follows we focus on the FEDV estimates. All variables are still significant and have the expected sign, including the FTA variable. We note that in all cases the FTA variable has a positive and statistically significant effect on bilateral trade. This result is robust to the use of different estimation techniques or different samples of countries.

\footnotetext{
${ }^{12}$ See for instance, Soloaga and Winters (2001), Carrère (2006), Rault et al. (2007a, b).

$13 \approx \exp (0.204)-1$.
} 
Table 2 The impact of the association agreement on bilateral trade using an extended sample of countries, i.e. the CEEC-4 and additional countries which did not sign an FTA (Belarus, the Russian Federation and the Ukraine)

\begin{tabular}{llll}
\hline Variables & FEM & REM & FEVD \\
& $(1)$ & $(2)$ & $(3)$ \\
& $Y_{i j t}$ & $Y_{i j t}$ & $Y_{i j t}$ \\
\hline $\mathrm{GDP}_{i t}$ & $0.797(3.44)^{* * *}$ & $0.951(17.56)^{* * * *}$ & $0.797(7.25)^{* * *}$ \\
$\mathrm{GDP}_{j t}$ & $5.248(3.59)^{* * *}$ & $0.944(13.68)^{* * *}$ & $5.248(4.67)^{* * *}$ \\
Dist $_{i j}$ & $0.000()$. & $-1.170(7.15)^{* * *}$ & $-1.104(6.48)^{* * *}$ \\
$\mathrm{GDPC}_{i t}$ & $0.693(2.49)^{* *}$ & $0.879(12.34)^{* * *}$ & $0.693(2.56)^{* *}$ \\
$\mathrm{GDPC}_{j t}$ & $1.051(2.03)^{* *}$ & $2.929(13.78)^{* * *}$ & $1.051(2.13)^{* *}$ \\
Llk $_{i j}$ & $0.000()$. & $-0.085(1.72)^{*}$ & $-0.114(3.03)^{* * *}$ \\
Stp $_{i t}$ & $0.106(3.11)^{* * *}$ & $0.004(1.71)^{*}$ & $0.106(2.01)^{* *}$ \\
Acc $_{i j t}$ & $0.164(4.29)^{* * *}$ & $0.297(7.74)^{* * *}$ & $0.164(5.01)^{* * *}$ \\
Constant & $-23.414(15.44)^{* * *}$ & $-13.694(13.20)^{* * * *}$ & $-19.707(124.16)^{* * *}$ \\
Observations & 1,470 & 1,470 & 1,470 \\
$R$-squared & 0.82 & 0.64 & 0.85 \\
Fischer Prob $>F$ & $13.80(0.04)$ & - & - \\
Hausman Prob $>\chi^{2}$ & - & $230.23(0.00)$ & - \\
\hline As expaind & & & \\
\hline
\end{tabular}

As explained in the main text, the FEVD method is the preferred one, the others (FEM and REM) are reported for comparison purposes and to check the robustness of the results to the estimation technique used

Absolute value of $t$ statistics in parentheses

* Significant at $10 \%$; ** Significant at $5 \%$; *** Significant at $1 \%$

We also made a comparison between trade between the EU and the countries that signed an FTA (i.e. the CEEC-4) and some others that did not, and estimated for this purpose Eq. 14 that includes two dummy variables. Our econometric results (see Table 3) indicate that both dummies are significant at the $1 \%$ level, which suggests that members countries are more inclined to trade amongst themselves than with other countries which are not part of the association agreement. Moreover, the estimated coefficients of the $\mathrm{Acc}_{\mathrm{ijt}}$ and $\mathrm{Accn}_{\mathrm{ijt}}$ dummy variables are, respectively, 0.210 and 0.089 , which highlights that countries which have signed an association agreement trade $14.0 \%{ }^{14}$ more than those without such an agreement (see Table 3 ).

As for robustness to using alternative estimation techniques, one can see that the estimated coefficients are similar for FEM and FEVD; however, the latter not only enables us to isolate the endogeneity of the association agreement variable and to obtain unbiased coefficients, but also captures the effects of time-invariant variables on trade flows.

The Fisher test suggests the introduction of effects (fixed or random) to improve the estimation results. The estimated coefficients of the FEM are different from those obtained with the REM (for instance, association agreement) which can be explained by the existence of a correlation between some explanatory variables and

$\overline{14 \approx(\exp (0.21)-1)-(\exp (0.09)-1)}$ 
Table 3 The impact of the association agreement on bilateral trade using an extended sample of countries including the CEEC-4 and additional countries which did not conclude an FTA

Absolute value of $t$ statistics in parentheses

* Significant at $10 \%$;

** Significant at 5\%;

*** Significant at $1 \%$

\begin{tabular}{ll}
\hline Variables & FEVD \\
& $Y_{i j t}$ \\
\hline $\mathrm{GDP}_{i t}$ & $1.118(24.82)^{* * * *}$ \\
$\mathrm{GDP}_{j t}$ & $6.937(11.64)^{* * *}$ \\
Dist $_{i j}$ & $-4.270(62.67)^{* * *}$ \\
$\mathrm{GDPC}_{\text {it }}$ & $1.209(1.74)^{*}$ \\
$\mathrm{GDPC}_{j t}$ & $3.421(74.12)^{* * *}$ \\
$\mathrm{Llk}_{i j}$ & $-0.189(4.55)^{* * *}$ \\
$\mathrm{Stp}_{i t}$ & $0.057(2.12)^{* *}$ \\
Acc $_{i j t}$ & $0.210(12.77)^{* * * *}$ \\
Accn & \\
Constant $_{i j t}$ & $0.089(3.54)^{* * *}$ \\
Observations & $-8.770(108.29)^{* * *}$ \\
$R$-squared & 1,995 \\
\hline
\end{tabular}

the bilateral specific effect. Moreover, the Hausman test rejects the null assumption of no correlation between the individual effects and some explanatory variables for all estimations. This implies endogeneity bias, and therefore the fixed effects model is preferred. The Davidson-MacKinnon test of exogeneity ( $F=160.26$, $P$ value $=0.00)$, confirm the endogeneity of the FTA. We also calculate the variance inflation factor (VIF) to ensure that multicollinearity does not affect the quality of estimates. In our all estimates, VIF did not exceed the threshold of 10, indicating that there is no multicollinearity. ${ }^{15}$

Overall, the agreement variable coefficient indicates a positive and statistically significant impact on bilateral trade in all cases.

\section{Conclusions}

This paper has analysed the impact of association agreements on trade flows between the EU-15 and CEEC-4 countries treating the agreement variable as endogenous and using appropriate panel methods to estimate a gravity equation. The most relevant estimates are those provided by the FEVD estimation method, which is the most appropriate for our purposes. This method permits to obtain unbiased coefficients and to capture the effects of time-invariant variables. As theory suggests, association agreements were found to have a positive and significant impact on trade flows between the participant countries.

To check the robustness of the effects on trade of FTAs we have also included in our sample a control group of countries (Belarus, the Russian Federation and the Ukraine), i.e. three countries, which belonged in the past to the Communist bloc and have then introduced market reforms but did not sign an FTA with the EU. It must be emphasised that in all our estimations (conditional to other variables) the FTA

\footnotetext{
15 A variance inflation factor value higher than 10 reveals the presence of multicollinearity requiring specific corrections (Gujarati 1995).
} 
variable has a positive and statistically significant effect on bilateral trade regardless of the estimation technique or sample of countries chosen, which provide evidence of the robustness of our results.

A comparison of trade between the EU-15 and the countries that signed an FTA (i.e. the CEEC-4) and some others that did not, specifically Belarus, the Russian Federation and the Ukraine, using two dummy variables, suggest that countries with an association agreement trade $14.0 \%$ more than the others, which do not have one. This result is consistent with theory and the experience of these countries. Indeed, in the case of the CEEC-4, following the FTA, within a few years the EU became their main commercial partner. The relative weight of CEEC-4 trade with the EU-15 was approximately $37 \%$ in 1990; 60\% in 2000 and $74 \%$ in 2005, whereas for Belarus, the Russian Federation and the Ukraine it was around 33\% in 1992 and 38\% in 2005 , and it has remained low and almost constant since then.

Acknowledgments We are very grateful to a referee and a member of the Advisory Board for helpful remarks and suggestions on an earlier draft of this paper.

\section{References}

Aitken, N. D. (1973). The effect of the EEC and EFTA on European trade: A temporal cross-section analysis. American Economic Review, 63(5), 881-892.

Anderson, J. E. (1979). A theoretical foundation for the gravity equation. American Economic Review, 69(1), 106-116.

Baier, S. L., \& Bergstrand, J. H. (2004). Economic determinants of free-trade agreements. Journal of International Economics, 64(1), 29-63.

Baier, S. L., \& Bergstrand, J. H. (2007). Do free trade agreements actually increase members' international trade? Journal of International Economics, 71(1), 72-95.

Baldwin, R. E. (1994). Towards an integrated Europe. London: CEPR.

Bergstrand, J. H. (1985). The gravity equation in international trade: Some microeconomic foundations and empirical evidence. Review of Economics and Statistics, 67(3), 474-481.

Bergstrand, J. H. (1989). The generalized gravity equation, monopolistic competition, and the factorproportions theory in international trade. Review of Economics and Statistics, 71(1), 143-153.

Bhagwati, J., \& Panagariya, A. (1996). The theory of preferential trade agreements: Historical evolution and current trends. American Economic Review, 86(2), 82-87.

Carrère, C. (2006). Revisiting the effects of regional trading agreements on trade flows with proper specification of the gravity model. European Economic Review, 50(2), 223-247.

Cooper, C. A., \& Massell, B. F. (1965). A new look at customs union theory. Economic Journal, 75(300), 742-747.

De Melo, J., Panagariya, A., \& Rodick, D. (1993). The new regionalism: A country perspective. Policy research working paper series 1094. Washington: The World Bank.

Egger, P. (2000). A note on the proper econometric specification of the gravity equation. Economics Letters, 66(1), 25-31.

Egger, P. (2002). An econometric view on the estimation of gravity models and the calculation of trade potentials. The World Economy, 25(2), 297-312.

Egger, P., \& Pfaffermayr, M. (2003). The proper panel econometric specification of the gravity equation: A three-way model with bilateral interaction effects. Empirical Economics, 28(3), 571-580.

Egger, P., \& Pfaffermayr, M. (2004). Distance, trade and FDI: A SUR Hausman-Taylor approach. Journal of Applied Econometrics, 19(2), 227-246.

Eichengreen, B., \& Irwin, D. A. (1995). Trade blocs, currency blocs and the reorientation of world trade in the 1930s. Journal of International Economics, 38(1-2), 1-24.

Fernández, R., \& Portes, J. (1998). Returns to regionalism: An analysis of non traditional gains from regional trade agreements. World Bank Economic Review, 12(2), 197-220. 
Frankel, J. A. (1997). Regional trading blocs in the world economic system. Washington: Institute for International Economics.

Frankel, J. A., \& Wei, S.-J. (1998). Open regionalism in a world of continental trade blocs. IMF Staff Papers, 45(3), 440-453.

Frankel, J. A., Stein, E., \& Wei, S.-J. (1996). Regional trading arrangements: Natural or supernatural. American Economic Review, 86(2), 52-56.

Ghosh, S., \& Yamarik, S. (2004). Are regional trading arrangements trade creating? An application of extreme bounds analysis. Journal of International Economics, 63(2), 369-395.

Glick, R., \& Rose, A. K. (2002). Does a currency union affect trade? The time series evidence. European Economic Review, 46(6), 1125-1151.

Grossman, G. M., \& Helpman, E. (1995). The politics of free-trade agreements. American Economic Review, 85(4), 667-690.

Gujarati, D. N. (1995). Basic econometrics (3rd ed.). New York: McGraw-Hill.

Hausman, J. A., \& Taylor, W. E. (1981). Panel data and unobservable individual effects. Econometrica, 49(6), 1377-1398.

Helpman, E., \& Krugman, P. (1985). Market structure and foreign trade: Increasing returns, imperfect competition, and the international economy. Cambridge: MIT Press.

Hsiao, C. (2003). Analysis of panel data (2nd ed.). Cambridge: Cambridge University Press.

Johnson, H. (1965). An economic theory of protectionism, tariff bargaining and the formation of customs union. Journal of Political Economy, 73(3), 256-283.

Krugman, P. (1991). Geography and trade. Cambridge: MIT Press.

Linnemann, H. (1966). An Econometric Study of International Trade Flows. Amsterdam: North-Holland.

Magee, C. (2003). Endogenous preferential trade agreements: An empirical analysis. Contributions to economic analysis and policy, 2(1), article 15. Berkeley Electronic Press.

Matyas, L. (1997). Proper econometric specification of the gravity model. The World Economy, 20(3), 363-368.

Plümper, T., \& Troeger, V. E. (2004). The estimation of time-invariant variables in panel analyses with unit fixed effects. Social Science Research Network, Working Paper.

Pöyhönen, P. (1963). A tentative model for the volume of trade between countries. Weltwirtschaftliches Archiv, 90(1), 93-100.

Rault, C., Sova, A., Sova, R. (2007a). The endogeneity of association agreements and their impact on trade for Eastern countries: Empirical evidence for Romania. Working Paper No. 868. William Davidson Institute, University of Michigan.

Rault, C., Sova, R., Sova, A. (2007b). The role of association agreements within European Union enlargement to Central and Eastern European countries. IZA Discussion Paper No. 2769. Institute for the Study of Labor, Bonn.

Rose, A. K. (2004). Do we really know that the WTO increases trade? American Economic Review, 94(1), 98-114.

Schiff, M., \& Winters, L. A. (1998). Regional integration as diplomacy. World Bank Economic Review, 12(2), 271-295.

Soloaga, I., \& Winters, L. A. (2001). Regionalism in the nineties: What effect on trade? North American Journal of Economics and Finance, 12(1), 1-29.

Tinbergen, J. (1962). Shaping the world economy: Suggestions for an international economic policy. New York: Twentieth Century Fund.

Viner, J. (1950). The customs union issue. New York: Carnegie Endowment for International Peace.

Wonnacott, P., \& Lutz, M. (1989). Is there a case for free trade areas? In J. Schott (Ed.), Free trade areas and US trade policy. Washington: Institute for International Economics.

Wooldridge, J. M. (2002). Econometric analysis of cross section and panel data (2nd ed.). Cambridge: MIT Press. 